\title{
Perfil das mulheres em situação de prostituição na cidade de Conselheiro Lafaiete - Minas Gerais: atuação da Estratégia de Saúde da Família ante a prevenção de doenças
}

\author{
Alan Rodrigues de Souza, Graziele Carolina de Almeida Marcolin, Mateus Marcolin, Leilane Paula \\ Dias Ramalho, Amanda Conrado Silva Barbosa
}

\section{Resumo}

A prostituição se confunde com a história da humanidade, sem distinção entre cultura, religião e sexualidade, tornando-se elemento de preconceito na sociedade atual. No entanto, ações de promoção da saúde e prevenção de doenças dessa categoria profissional devem ser estimuladas, trabalhando prol o controle de Doenças Sexualmente Transmissíveis (DST) e melhorando a qualidade de vida dessas mulheres. O presente estudo tem por objetivo descrever o perfil das mulheres em situação de prostituição da cidade de Conselheiro Lafaiete - MG, assim como seu conhecimento acerca do processo de prevenção de doenças. A metodologia utilizada foi estudo original, de porte descritivo, com abordagem exploratória qualitativa, havendo integração de questionário semi-estruturado. A amostra constituiu de doze prostitutas que atuam no Município de Conselheiro Lafaiete - MG, com faixa etária de 23 a 37 anos. Foi explanado para as entrevistadas a finalidade e processo da pesquisa, sendo posteriormente fornecido e assinado o termo de consentimento livre e esclarecido. Com vistas aos resultados, tem-se que o perfil das profissionais apresenta as seguintes características: baixa escolaridade; em sua maioria são solteiras; não tem filhos; a família não sabe da profissão que exercem; são mantenedoras da família e de si própria; apresentam renda familiar inferior ou igual a dois salários mínimos; a principal motivação para integração na profissão foi o dinheiro; a clientela é exclusivamente constituída por homens; atendem em média 5 clientes por dia; normalmente gastam seu dinheiro para o pagamento de despesas pessoais e da família. Questionadas acerca das questões correlatas ao cuidado com a saúde, em sua maioria desconhecem as DST; procedem constantemente relações sexuais desprotegidas; visualizam a não aceitabilidade e preconceito existente nos mecanismos de saúde; buscam o médico apenas em atendimentos emergenciais; sentem por não haver um serviço exclusivo, mais acolhedor e humanizado, para o atendimento de profissionais do sexo. Com relação ao preconceito, compreendem que a sociedade não está preparada para aceitação de tal profissão, sentindo-se discriminadas e desiludidas com a mesma. Sentem desejo de "sair dessa vida", mas não o fazem devido aos ganhos envoltos à profissão. Logo, diante do perfil e das demandas mais peculiares apresentadas, percebe-se que o preconceito é significativo e que boa parte das prostitutas apresenta dificuldades em sua vida pessoal e cuidados com a saúde. $\mathrm{O}$ acesso aos serviços básicos de saúde na cidade é precário, não tendo suporte e preparo para atender estas profissionais. Assim, os profissionais de saúde, principalmente o Enfermeiro, devem estar preparados para lidar com situações diferenciadas, onde o preconceito e percepções errôneas podem agravar o estado que se encontram as profissionais do sexo. Ademais, a sua importância é fundamental na promoção da saúde e deve contribuir nas ações da atenção primária dentro da ESF, voltando-se à prática de atividades sexuais mais seguras, incluindo tais profissionais nos serviços de saúde por meio de informações em prevenção de DST, promoção da saúde, auto-cuidado, tratamento de doenças, prevenção ao uso de drogas, dentre outros; agindo como educador, sem preconceito ou discriminação, a fim de promover a saúde e contribuir para a eliminação do preconceito existente.

Descritores: Profissionais do Sexo; Prevenção; Saúde. 